\title{
SARS-CoV-2 is not detectable in cervicovaginal secretions from women with active COVID-19 infection- a pilot study
}

\author{
Pankush Gupta $^{1}$, Aashish Choudhary ${ }^{1}$, Deepankar Srigyan ${ }^{1}$, Neena Malhotra ${ }^{1}$ \\ ${ }^{1}$ All India Institute of Medical Sciences- New Delhi, India
}

\begin{abstract}
Objective: To detect the shedding of SARS-CoV-2 in cervicovaginal secretions of women with active COVID 19 infection.

Methods: A cross-sectional study from a COVID facility including women aged 20-45 years with active COVID-19 infection, cervicovaginal secretions were collected from cervix and posterior fornix using dacron swab within 7 days of symptom onset or 5 days of nasopharyngeal rRTPCR test positivity in asymptomatic women. Cervicovaginal samples of women with mild symptoms were tested using rRT-PCR for SARS-CoV-2.

Results: SARS-CoV-2 was not detected in cervicovaginal secretions of any of the 11 women included in the study.

Conclusions: SARS-CoV-2 does not shed in the cervicovaginal secretions of women with mild COVID 19 infection, ruling out sexual and vertical transmission of virus in mild and asymptomatic disease.
\end{abstract}

Keywords: cervicovaginal secretion, COVID-19, SARSCoV-2

\section{INTRODUCTION}

Severe acute respiratory syndrome coronavirus 2 (SARS-CoV-2) has severely affected the world. The disease pathogenesis has been well elucidated but despite the various acceptable modes, transmission via sexual contact remains unresolved. The virus binds to Angiotensin converting enzyme 2 (ACE 2) receptors, leading to the disease manifestations (Yue et al., 2020). ACE 2 receptors have been isolated from various body parts, including the testis - which formed the basis for viral transmission in the semen (Mohseni et al., 2020). However, studies to date have found otherwise (Holtmann et al., 2020). SARS-CoV-2 in vaginal secretions has also been studied with conflicting results (Cui et al., 2020; Qiu et al., 2020; Aslan et al., 2020; Schwartz et al., 2021). There is of ACE 2 receptors expression in the endometrium, suggesting the possible shedding of virus in cervicovaginal secretions (Henarejos-Castillo et al., 2020). Previous viral shedding of other viruses from the coronavirus family has been seen in vaginal secretions, as well as their transmission to the fetus (Gagneur et al., 2008). Given the structural homology of the SARS-CoV-2 with other coronaviruses, it may be hypothesized that it sheds in cervicovaginal secretions, and it may play a role in sexual and vertical transmissions. Hence, we planned this study to assess the viral shedding in cervicovaginal secretions that could throw light on other modes of virus transmission including, sexual and vertical.

\section{MATERIALS AND METHODS}

This cross-sectional study was conducted between October 2020 - December 2020 at a tertiary care hospital that was converted into a dedicated COVID hospital during the pandemic. The women included were between 20-45 years of age with SARS-CoV-2 infection, confirmed by RT-
PCR on nasopharyngeal swabs and mild symptoms within 7 days of onset. We also included the asymptomatic women within 3-5 days of testing positive on RT-PCR. We excluded women with moderate-severe disease, with comorbidities or during their menstrual period. Women after informed written consent underwent a per speculum examination by trained personnel. Cervicovaginal secretions were collected with two dacron swabs, one inserted into the cervix and rotated 360 degrees for 3-4 times and another inserted into the posterior fornix to collect vaginal secretions. Adequate PPE was given to those handling and transporting the cervicovaginal samples.

Collected cervicovaginal swab specimens were inoculated into $3 \mathrm{ml}$ of Viral Transport Medium (HiMedia laboratories, India), labelled with the patient's information and transported in an icebox immediately to the dedicated SARS-CoV-2 detection laboratory, at the All India Institute of Medical Sciences, New Delhi.

\section{Laboratory procedure}

All the specimens were processed in a class II, Type A2 biological safety cabinet with biosafety level-2 (BSL2) work practices. The transport tubes were briefly vortexed to homogenize the specimen with the viral transport medium. After removing the swab from the transport medium, the samples were centrifuged at 3000 rpm for 5 minutes. Then the transport tube contents were aliquoted in two 1 $\mathrm{ml}$ aliquots in pre-labelled screw-capped storage vials and stored at $-80^{\circ} \mathrm{C}$ until testing.

RNA extraction and Real-Time RT-PCR Assay:

RNA was extracted from the cervicovaginal swab specimens using the QIAamp Viral RNA Mini Kit (Qiagen, Cat. No. 52906). RNA was extracted from $200 \mu \mathrm{l}$ of the specimen and eluted in $30 \mu \mathrm{l}$ of elution buffer provided with the extraction kit. The RNA was reversely transcribed and amplified using an FDA-EUA approved, ICMR-NIV multiplex single tube SARS-CoV-2 RT-PCR assay (India) in Agilent AriaMx Real-Time PCR system. The results were interpreted as per the manufacturer's instruction provided within the PCR kit.

\section{RESULTS}

Our study had 11 sexually active females admitted with mild disease. The baseline characteristics are summarized in Table 1 . The virus was not detectable in the cervicovaginal secretions of these women. Husbands of four out of these 11 females were also positive and their semen samples were also collected for and tested for virus shedding, which also did not detect the virus.

\section{DISCUSSION}

Our study intended to define other modes of SARSCoV-2 virus transmission. In our study cohort of women in the active phase of disease, no viral shedding was seen in the cervicovaginal secretions; thus, suggesting against female to male transmission of virus through sexual contact, and from mother to child during vaginal delivery. 


\begin{tabular}{|l|c|}
\hline Table 1. Baseline characteristics of enrolled participants $(n=11)$. \\
\hline Variable & $34 \pm 5.65$ \\
\hline Age (years) (Mean \pm SD) & $22.9 \pm 1.33$ \\
\hline BMI $\left(\mathrm{Kg} / \mathrm{m}^{2}\right)($ Mean $\pm \mathrm{SD})$ & 2 \\
\hline Duration of symptoms (days) (Median) & 63.6 \\
\hline Symptomatic $(\%)$ & $4.0 \pm 0.89$ \\
\hline Time from symptom onset to cervicovaginal swab (days) (Mean $\pm \mathrm{SD})$ & 3 \\
\hline Time from testing to cervicovaginal swab (days) (Median) & \\
\hline
\end{tabular}

BMI - Body Mass Index, SD- Standard deviation.

Coronavirus attaches to ACE 2 receptors in different organs through a spike protein, causing its fusion with cell membranes and endocytosis (Henarejos-Castillo et al., 2020). A TMPRSS protease cleaves the S protein, which further causes its binding to ACE2 receptors. Other proteases, such as the Cathepsin B , L , FURIN, MX1, Basigin (BSG) have also been shown to play a role in increasing Coronavirus infectivity. A study by Henajeros-Castillo et al. tried to find the expression of these various proteins in the endometrium of healthy patients to assess the vulnerability of the endometrium to this virus, and they found high gene expression of TMPRSS4, CTSL, CTSB, FURIN, MX1 and BSG in the endometrium. Although ACE2 expression was low, it increased towards the implantation window and with age, suggesting endometrial susceptibility to CoV-2 more in the elderly with possible cervical shedding (Henarejos-Castillo et al., 2020). The SARS CoV-2 Genome is $89 \%$ like that of other coronaviruses, such as the HCoV-229E, which have already been proven to infect the vagina and transmit sexually, and even cause vertical transmission (Gagneur et al., 2008). Therefore, we can speculate that the transmission potential of CoV- 2 will be like that of other viruses of the family. These findings are refuted by a recent study by Cui et al., where they pointed out that the ACE2 receptors are not expressed in cervical and vaginal tissues, so females do not transmit the virus sexually or during delivery to the baby through vaginal secretions (Cui et al., 2020). Another study by Qiu et al. in postmenopausal women with severe disease, also evaluated vaginal secretions obtained between 17-49 days after infection but did not find any positive sample (Qiu et al., 2020). Aslan investigated 12 pregnant women with moderate disease for positivity in vaginal secretions and did not find the virus in the secretions (Aslan et al., 2020). Only one study, by Schwartz et al., detected the SARS-CoV-2 in vaginal secretions with acute infection in mild disease in 2/35 women, one premenopausal and one postmenopausal (Schwartz et al., 2021).

The present study has some limitations, such as the small sample size, non-inclusion of postmenopausal women and women with severe disease. Despite these limitations, the present study surely provides evidence concerning the absence of the virus in cervicovaginal secretions and no risk of fetal affliction in mild disease. Future studies should aim to include more patients with severe disease to reach a conclusion.

\section{CONCLUSION}

No shedding of SARS-CoV-2 virus occurs in cervicovaginal secretions in women with mild disease, pointing against sexual or vertical transmission of the virus.

\section{Funding}

The study was funded by Intramural Research Grant from All India Institute of Medical Sciences, New Delhi (F.8A-COVID-56/2020/RS).

\section{ACKNOWLEDGEMENT}

To Dr. Anne Monga and Dr. Deepika Kashyap for helping in sample collection.

\section{CONFLICT OF INTEREST}

None

\section{Corresponding author:}

Neena Malhotra

All India Institute of Medical Sciences

New Delhi, India

E-mail: malhotraneena@yahoo.com

\section{REFERENCES}

Aslan MM, Uslu Yuvacı H, Köse O, Toptan H, Akdemir N, Köroğlu M, Cevrioğlu AS, Özden S. SARS-CoV-2 is not present in the vaginal fluid of pregnant women with COVID-19. J Matern Fetal Neonatal Med. 2020:1-3. Online ahead of print PMID: 32669014 DOI: 10.1080/14767058.2020.1793318

Cui P, Chen Z, Wang T, Dai J, Zhang J, Ding T, Jiang J, Liu J, Zhang C, Shan W, Wang S, Rong Y, Chang J, Miao X, Ma X, Wang $S$. Clinical features and sexual transmission potential of SARS-CoV-2 infected female patients: a descriptive study in Wuhan, China. medRxiv [Preprint]. 2020. DOI: $10.1101 / 2020.02 .26 .20028225$

Gagneur A, Dirson E, Audebert S, Vallet S, Legrand-Quillien MC, Laurent Y, Collet M, Sizun J, Oger E, Payan C. Materno-fetal transmission of human coronaviruses: a prospective pilot study. Eur J Clin Microbiol Infect Dis. 2008;27:863-6. PMID: 18373106 DOI: $10.1007 /$ s10096-008-0505-7

Henarejos-Castillo I, Sebastian-Leon $P$, Devesa-Peiro A, Pellicer A, Diaz-Gimeno P. SARS-CoV-2 infection risk assessment in the endometrium: viral infection-related gene expression across the menstrual cycle. Fertil Steril. 2020;114:223-32. PMID: 32641214 DOI: $10.1016 / j$.fertnstert.2020.06.026

Holtmann N, Edimiris $P$, Andree $M$, Doehmen $C$, BastonBuest D, Adams O, Kruessel JS, Bielfeld AP. Assessment of SARS-CoV-2 in human semen-a cohort study. Fertil Steril. 2020;114:233-8. PMID: 32650948 DOI: 10.1016/j.fertnstert.2020.05.028

Mohseni AH, Taghinezhad-S S, Xu Z, Fu X. Body fluids may contribute to human-to-human transmission of severe acute respiratory syndrome coronavirus 2: evidence and practical experience. Chin Med. 2020;15:58. PMID: 32514291 DOI: 10.1186/s13020-020-00337-7 
Qiu L, Liu X, Xiao M, Xie J, Cao W, Liu Z, Morse A, Xie Y, Li T, Zhu L. SARS-CoV-2 Is Not Detectable in the Vaginal Fluid of Women With Severe COVID-19 Infection. Clin Infect Dis. 2020;71:813-7. PMID: 32241022 DOI: 10.1093/cid/ciaa375

Schwartz A, Yogev Y, Zilberman A, Alpern S, Many A, Yousovich R, Gamzu R. Detection of severe acute respiratory syndrome coronavirus 2 (SARS-CoV-2) in vaginal swabs of women with acute SARS-CoV-2 infection: a prospective study. BJOG. 2021;128:97100. PMID: 33021026 DOI: 10.1111/1471-0528.16556
Yue $H$, Bai X, Wang J, Yu Q, Liu W, Pu J, Wang X, Hu J, Xu D, Li X, Kang N, Li L, Lu W, Feng T, Ding L, Li X, Qi X; Gansu Provincial Medical Treatment Expert Group of COVID-19. Clinical characteristics of coronavirus disease 2019 in Gansu province, China. Ann Palliat Med. 2020;9:1404-12. PMID: 32692208 DOI: 10.21037/ apm-20-887 